\title{
Synapses, Quantum Theory and Panpsychism
}

\begin{abstract}
C.U.M. Smith
Abstract

The introduction situates the 'hard problem' in its historical context and argues that the problem has two sides: the output side (the Kant-Eccles problem of the freedom of the Will) and the input side (the problem of qualia). The output side ultimately reduces to whether quantum mechanics can affect the operation of synapses. A discussion of the detailed molecular biology of synaptic transmission as presently understood suggests that such affects are unlikely. Instead an evolutionary argument is presented which suggests that our conviction of free agency is an evolutionarily induced illusion and hence that the Kant-Eccles problem is itself illusory. This conclusion is supported by wellknown neurophysiology. The input side, the problem of qualia, of subjectivity, is not so easily outflanked. After a brief review of the neurophysiological correlates of consciousness (NCC) and of the Penrose-Hameroff microtubular neuroquantology it is again concluded that the molecular neurobiology makes quantum wave-mechanics an unlikely explanation. Instead recourse is made to an evolutionarily- and neurobiologically-informed panpsychism. The notion of an 'emergent' property is carefully distinguished from that of the more usual 'system' property used by most dual-aspect theorists (and the majority of neuroscientists) and used to support Llinas' concept of an 'oneiric' consciousness continuously modified by sensory input. I conclude that a panpsychist theory, such as this, coupled with the non-classical understanding of matter flowing from quantum physics (both epistemological and scientific) may be the default and only solution to the problem posed by the presence of mind in a world of things.
\end{abstract}

Key Words: Synapses, quantum theory, panpsychism, qualia, oneiric consciousness, free will, complexity, emergence

NeuroQuantology 2008; 2:164-174

'It is an old maxim of mine that when you have excluded the impossible, whatever remains, however improbable, must be the truth'

Sherlock Holmes in 'The Adventure of the Beryl Coronet', Strand Magazine, 1892

\section{Introduction ${ }^{1}$}

The problem of mind or, in modern phraseology, the 'hard problem', has very deep roots in Western culture. It was, however, only sharply exposed by the

Corresponding author: C.U.M. Smith

Address: Vision Sciences, Aston University, Birmingham B4 7ET, UK

e-mail: c.u.m.smith@aston.ac.uk scientific revolution of the seventeenth century. Galileo sought to deflect ecclesiastical anger by insisting that whilst his science was far preferable to its Aristotelian competitor in accounting for the things of this world, the things of the spirit were best left to 'a higher science than ours'. René Descartes in a similar spirit of reconciliation sharply distinguished an immaterial 'mind', 
res cogitans, from a material body, res extensa, where his hydraulic physiology obtained. But these attempts to escape ecclesiastical censure necessarily failed. The question was inevitably asked: where do mind and matter interact? Descartes pointed to the pineal. This, of course, only led to the next question: how?

Brain science has travelled an immense distance since the seventeenth century. Yet, as many have remarked, the basic understanding of the brain as a material system has not altered. Similarly our basic self-understanding has not altered. We understand ourselves as free agents and we understand ourselves to be conscious beings, subject to pains and pleasures, colours, sounds, odours, tastes and all the other 'qualia' of everyday living. The problem posed by the seventeenth century has not withered away, as have so many others, but, if anything, has become starker.

There are thus two parts to the "hard problem': the output part, i.e., how can we reconcile our conviction that we are free agents with the iron laws of determinism which (seemingly) control the workings of the brain; and, secondly, the input part, i.e., how can we reconcile the varied qualia we live through' daily with the material substratum of the brain? It has often been said that the problem is insoluble within the framework of classical, post-seventeenth century, science. As indicated above this science originated in a sharp and purposeful exclusion of consciousness. It is thus hardly a surprise that no way can be found to account for it within its contemporary lineal successor.

There was, however, as we know, a revolutionary departure from classical physics at the beginning of the twentieth century. It was found that the concepts derived from the seventeenth-century revolution, the concepts of Descartes, Newton and many others, were inapplicable to the world of the very small. Indeed the founding fathers of this postclassical physics, quantum physics, saw no way of proceeding without bringing in the consciousness of the observer - anathema to classical physics. It consequently occurred to a number of these revolutionaries that we might have here a fresh and viable approach to the mind-matter problem of neuropsychology (Smith, 2006).

Many have observed that modern neuroscience is fully within the mechanistic paradigm first promulgated by René Descartes in L'Homme and elsewhere (Huxley, Woodger, Blakemore etc.). As such it must, at some level, be open to quantum effects. Where could this be, and could it provide a solution to the 'hard problem' of the relation of mind and brain? Two major answers to this question have been proposed: the synapse and the microtubule.

\section{Synapses}

Our understanding of synapses has increased hugely since the term was coined by Sherrington in the 1890s. They are now recognised to be organelles of immense biochemical and molecular biological complexity, so much so that they form the subject matter of an entire journal, Synapse, published monthly as well as figuring largely in many other neuroscientific publications. As Lisman, Raghavachan and Tsien (2007) remark, there are nowadays specialists who devote their research careers to one side of the synaptic cleft and others who direct their careers entirely to the other! The depth of our understanding has increased hugely since Sherrington's time and also since the early 1990s when Beck and Eccles published his final papers on NeuroQuantology (Beck, 2008; Eccles, 1990; 1994; Beck and Eccles, 1992).

Eccles' objective was to save human agency from the seemingly iron laws of physical determinism. It was an objective very similar to that which motivated Immanuel Kant in the Critiques he published at the end of the eighteenth century. It will be remembered that engraved upon his tombstone was the problem with which he had tussled all his life, how to reconcile the Newtonian determinism of 'the starry heavens above' with the subjective conviction of free agency necessary for 'the moral law within'.

Why synapses? The SherringtonEccles tradition in twentieth-century neuroscience teaches that the flexibility of the brain resides in its synapses. The axons 
and dendrites of the brain, the perikarya and the glial cells, are all regarded as part of the 'hard-wiring'. They may, and certainly do, change, grow and decline, throughout life but the millisecond changes underlying willeddecisions can only be changes in synaptic transmission. Let us, then, look at the contemporary neurobiology of the synapse.

There are, of course, immense numbers of synapses in the human brain: some estimates suggest in excess of 100 billion $\left(10^{11}-10^{12}\right)$. In strong contrast to the junctions found in silicon-chip computers they differ hugely, one from another. Indeed it can be safely said that no two synapses out of these 100 billion are identical. They differ in size, in position on the post-synaptic cell, in transmitter substance used, and in a multitude of other ways. Some inhibit activity in the post-synaptic cell, others excite activity. In addition some synapses do not use transmitter substances at all but act directly on the post-synaptic cell by electrical transmission. This, then, is the first problem presented by the synapse to the NeuroQuantologist. Are all, or just some, of this multifarious crowd of synapses involved in quantum responses? Presumably it is just some, those involved in the output pathways underlying voluntary activity. But these output pathways are, of course, many and varied. Some precede to the vocal apparatus, some to the limbs, some to other bodily parts. How does the 'Will' select which synapses to actuate?

But supposing these initial difficulties are overcome, we come next to the synapse itself. Most, if not all NeuroQuantologists who suspect the synapse to be the locus of quantal interaction, assume that it is the chemical rather than the electrical variety that is subject to these effects. Chemical synapses are, as already mentioned, many and various. However, because of their small size and other difficulties, few synapses in the mammalian central nervous system have been subjected to detailed biophysical investigation. One which has proved particularly useful is the calyx of Held, a giant glutaminergic synapse in the mammalian auditory brain stem. Much of what is known of the fundamental biophysics of chemical synapses has been determined by using this preparation. Other large synapses are made by mossy fibers in the Cornu Ammonis region of the hippocampus and these, too, have proved invaluable to synaptologists.

The initial event in synaptic transmission at chemical synapses is the arrival of an action potential at the presynaptic terminal. This opens $\mathrm{P} / \mathrm{Q}-, \mathrm{N}-$ and R-type $\mathrm{Ca}^{2+}$ channels in the terminal's membrane. These channels differ in the pharmacological blocking agents which affect them and in susceptibility to modulation by G-proteins etc. Nevertheless their overall structure is much the same. They consist of a tetramer of sub-units grouped around an ion channel. An X-ray crystallographic solution to a type example of a $\mathrm{K}^{+}$-channel (the bacterial KcsA channel) was achieved by MacKinnon's lab, first at a $3.2 \AA$ resolution and then at $2 \AA$ resolution (Doyle, 1998). It provided a deep insight into the structural biophysics of this first step in synaptic transmission. The KcsA channel resembles an inverted wigwam with its base projecting on the extracellular side of the membrane and its apex projecting intracellularly. The selectivity pore is $12 \AA$ in length and some $3 \AA$ in diameter at the apex of the wigwam. The pore opens and closes by movement of the $\alpha$-helical walls at the base of the cone. In the closed position the $\alpha$-helical pores are closely apposed to each other. As the amino-acid residues projecting from the $\alpha$-helix are only about $4 \AA$ apart and are hydrophobic, the pore is effectively closed to small hydrophilic cations. But how is this movement caused by change in voltage across a membrane? The next step was, therefore, to crystallise and analyse a voltage-gated $\mathrm{K}^{+}$-channel. When this was done, also by MacKinnon's lab, it was shown that the central ion-conduction pore is surrounded by voltage sensitive 'paddles' which move in response to voltage changes across the membrane, opening and shutting the pore into the extracellular compartment (Jiang et al, 2003).

$\mathrm{Ca}^{2+}$-channels are, in essence, four $\mathrm{K}^{+}$channel subunits joined together. There is thus every reason to believe that the means of connecting voltage change across the membrane to the opening of the channel is 
analogous to that discovered in the $\mathrm{K}^{+}$channel tetramer. $\mathrm{Ca}^{2+}$ moves through the selectivity channel via two binding sites: a low affinity site near the extracellular entrance and a high affinity site further down the selectivity channel. When a $\mathrm{Ca}^{2+}$ ion arrives at the low affinity site its electrostatic field displaces the $\mathrm{Ca}^{2+}$ on the high affinity site which then, provided the pore is open, tumbles into the interior. The through-put in physiological conditions is very high. $\mathrm{Ca}^{2+}$ channels are clustered around synaptic vesicles in the presynaptic terminal. The arrival of an action potential thus opens a small group of these channels and $\mathrm{Ca}^{2+}$ pours into a 'microdomain' (diameter about $200 \mathrm{~nm}$ ) surrounding a vesicle. In central glutaminergic synapses it has been found that the $\mathrm{Ca}^{2+}$ concentration in the microdomain surrounding a synaptic vesicle rises to between $10 \mu \mathrm{M}$ and $25 \mu \mathrm{M}$ for some $300 \mu \mathrm{sec}$ after the opening of the $\mathrm{Ca}^{2+}$ gates is triggered, i.e. between 2.5 and $63 \times 10^{10} \mathrm{Ca}^{2+}$ ions are released into the $200 \mathrm{~nm}$ microdomain. After the $\mathrm{Ca}^{2+}$ channel closes, $\mathrm{Ca}^{2+}$ rapidly diffuses out of the microdomain and is sequestered elsewhere in the terminal.

$\mathrm{Ca}^{2+}$ ions bind to synaptotagmin sensors on vesicle membranes. Four to five such cations bind to a synaptotagmin molecule and activate it in a co-operative fashion. Each vesicle membrane presents about fifteen synaptotagmin molecules to the $\mathrm{Ca}^{2+}$ microdomain. They act together with a whole complex of other molecules - SNAREs. VAMPs, SNAPs etc. to bind the vesicle membrane to the interior leaflet of the terminal membrane and cause the vesicle to shed its contents - neurotransmitter through a 1-2 nm fusion pore into the synaptic cleft. The formation of this fusion pore is still not fully understood. It is, however, clear that a complex biochemistry is involved. This is still being worked out and fortunately need not concern us in this paper (Smith 2002; Jackson and Chapman, 2006; Lisman et al., 2007).

\section{Can Quantum Fluctuations Influence Synaptic Exocytosis?}

Although at first Eccles believed that quantum fluctuations could affect the synaptic vesicle directly, he quickly realised that the numbers were against him and that any such phenomena would be quickly swamped by thermal agitation. NeuroQuantologists have subsequently looked at two places where quantum physics may affect the synapse - at the exocytotic fusion pore itself and at the $\mathrm{Ca}^{2+-}$ channel responsible for triggering the exocytotic process. In his last papers Eccles focused on the 'synaptic grid' which is visible in electronmicrographs of the interior of the presynaptic membrane. He collaborated with the quantum physicist Friedrich Block and argued that 'preparation for exocytosis means bringing the paracrystalline presynaptic grid into a metastable state from which exocytosis can occur' (Beck and Eccles, 1992). In his 1996 paper Beck discusses the quantum feasibility in detail although emphasising that it is the biophysics not the philosophical problem he is treating (Beck, 1996). Another twelve years of research into the molecular biology of synaptic excocytosis has shown, as indicated above, that the model envisaged by Eccles must be replaced by a far more complex biochemistry. It is difficult to see where quantum fluctuations would affect this more complex biochemistry in any significant way and thus affect the probability of exocytosis.

If quantum events cannot affect the intricate process of transmitter release perhaps they can influence the $\mathrm{Ca}^{2+}$ trigger for that release. This has been suggested by several quantum physicists including Henry Stapp. Stapp observed that at their narrowest point the $\mathrm{Ca}^{2+}$ channels are no more than 1 $\mathrm{nm}$ wide and that this would give a lateral uncertainty of about $1 \%$ of the ion's longitudinal velocity (Stapp, 2004, p.25). This, writes Stapp, affects the probability of the $\mathrm{Ca}^{2+}$ ion being absorbed on the triggering site on the presynaptic terminal. 'The quantum state of the brain' write Schwartz, Stapp and Beauregard (2005, p.11) 'has a part in which the neurotransmitter is released and another part in which it is not released. This quantum state occurs at every one of the trillions of terminals'. It is this 'smear' of possible quantum brain states which consciousness probes and 'reduces' from 
'potential' to 'actual'. Unfortunately, as we noted above, the $\mathrm{Ca}^{2+}$ channel opens at the base of the 'wigwam' to a width considerably more than $2 \mathrm{~nm}$ and four or five $\mathrm{Ca}^{2+}$ ions bind co-operatively to each of some fifteen synaptotagmin sensors before vesicle exocytosis is triggered. Stapp's theory is, in other respects, very interesting and includes as a central part the 'quantum Zeno' or 'watched-pot' effect which would, as he says, for the first time provide a place for consciousness in evolutionary theory (Stapp, 2004, p.30). However, as I have argued more fully elsewhere (see Smith, 2008), neither the Eccles/Beck nor the Stapp endeavours to find a locus for quantum fluctuations to make themselves felt in the molecular biology of the brain seem to me to take adequate account of the neurobiological reality revealed in recent research.

\section{Another Approach to the Free-Will Problem}

If the Kant-Eccles problem of free-will in a Newtonian universe is recalcitrant to solution by the new physics of Bohr, Heisenberg and Schrödinger can an alternative be devised? Let us look at a solution proposed by evolutionary biology.

Evidence based on mitochondrial DNA suggests that modern humans originated some 200.000 years ago on the savannahs of East Africa. Communication must have been at the centre of this early life style. Palaeoanthropologists tell us that they probably foraged in small bands of from 50 to 75 individuals. Hominids possessed neither the athleticism nor the natural weaponry of their fellow predators and prey. Co-operative tactics must have been the rule. Active hunting, scavenging, collecting would all have been group endeavours. Teaching, learning, imitation must have been at an evolutionary premium. This is reflected in the brain. Not only does the FOXP2 'language' gene show signs of strong evolutionary pressure over the last 200.000 years but the mirror neuron system in human brains is also very welldeveloped. This system provides a neurophysiological basis for imitative learning, for empathic understanding and also, it is argued, for the origin and evolution of natural language (Rizzolatti and Criaghero, 2004).

These developments all point toward the development of a 'theory of mind'. Indeed, there is evidence that some infrahuman primates also show rudiments of such a theory. All humans, however, with the possible exception of some extreme autistics, recognize the existence of 'minds' in other humans and sometimes attribute them to several other species of animal. Indeed primitives attribute 'minds' to phenomena which we would regard as inanimate. They might attribute 'intentionality' to lightning and thunder, to inundations and the skeins of bird flight. Once such attributions are made, once the behaviour of other members of the band is understood as the outcome of emotions and passions similar to those one experiences oneself, the world changes. Living in a close-knit band, once it is recognized that others resemble oneself, one quickly attributes to others the motives and intentions one feels oneself. Vice-versa one feels the gaze of others on oneself. Selfconsciousness emerges. The ego, as sociologists following George Herbert Mead argued long ago, is socially generated.

But in order to hold the group together, to survive on the open savannah, members of the band have to behave in a cooperative manner. How can this be ensured? Ethologists have examined the methods used by many social species to achieve cooperative behaviour (Wilson, 2000) but the Hominidae solved the problem in a unique way: by developing a deontic system based crucially on the supposition that other members of the band were 'free' agents, that they were, in other words, responsible for their actions. Once this was allowed the powerful attributes of praise and blame could be applied. Only within such an ethical framework could reciprocal altruism develop so that individuals in a band felt 'obliged' to act in a co-operative manner. Only in this way could the band survive the perils of the savannah. The band would fall apart if its members were unable to 'praise' or 'blame' their fellows, if its members did not regard each other as 'responsible' for their actions, if, in a word, they were not regarded as 'free'. 
Thus it can be seen that evolutionary pressures during the long ages of prehistory ensured that the notions of freedom and responsibility became deeply embedded at the core of the human psyche.

But if this is so, the balance of argument shifts towards accepting that our conviction that we are free agents is no more than an illusion. Indeed, the argument for illusion is strongly supported by neurophysiological studies such as those of Benjamin Libet (1999) which imply that consciousness comes late on the scene of a seemingly willed action. Perhaps Thomas Huxley was right when he described humans as 'conscious automata'! This does not, however, mean that we are 'zombies'. It does not mean that if we are told we are going to do something, we willy-nilly do it. It is only when the information is withheld from the agent that the hidden onlooker can predict. I have described this as the psephelogical argument (Smith, 1993). If the voter is told what the result of an election is going to be this information changes his voting behaviour. Similarly, if an individual is told what his future action is going to be this alters the complex of neurophysiological forces within his brain so that an earlier prediction is invalidated.

It seems to me, therefore, that the Eccles-Stapp effort to discover a gap in the iron law of physical determinism is not only neurobiologically questionable but also misconceived. There is no problem posed by the existence of the moral law in a deterministic universe: freedom of the will, however profoundly felt, is an evolutionarily ingrained illusion. Thus there is no need to delve into the recesses of synaptology to find loci where quantum mechanics could take hold.

\section{The Problem of Qualia}

The problem posed by the presence of qualia in a world of things is, however, not so easily solved. This, as mentioned in the introduction, is the second part of the 'hard' problem. The 'easy' part (better the 'tough' part) is identifying which activity in which part of the brain is associated with consciousness, in other words identifying the neural correlatives of consciousness (NCC). The first decade of the twenty-first century has seen a huge upsurge of interest in identifying these correlates. Numerous different ideas have been proposed (see Smith, 2008) but none have as yet received universal consent. Nevertheless, many investigators of the NCC have provided evidence that coherent oscillatory activity in the cortex underlies several forms of consciousness (Llinas et al, 1998 for review). In particular widespread $y$-band activity (30$70 \mathrm{~Hz}$ oscillations) is correlated with many conscious states.

This oscillatory activity has been correlated with quantum mechanics by the well-known work of Stuart Hameroff and Roger Penrose (Penrose, 1989; 1994; Hameroff and Penrose, 1996). In essence they propose that self-collapse of coherent quantum states spreading through quite large populations of neuronal microtubules creates states of consciousness. Each such collapse creates a conscious moment. Hameroff and Penrose calculate that the self-collapse of a coherent quantum state associated with microtubules connected through some 20.000 neurons would account for oscillations at $\gamma$-band frequencies. Consciousness thus consists of a rapid succession of conscious moments: some 40 every second. The Hameroff-Penrose conjecture has been subjected to fierce criticism from the quantum physics community (Tegmark, 2000; Siefe, 2000) and, as with the quantum synaptology discussed above, seems hardly to accord with contemporary molecular neurobiology (Smith, 2008). Most importantly, however, it is not obvious how the self-collapse of coherent quantum states is associated with the qualia we live through day by day. Penrose's original proposal pointed to the similarity between the 'non-computability' of quantum 'self-collapse' and mathematical intuition, not with the day to day subjectivity of the common man.

Nevertheless, in spite of the seeming incompatibility of the Penrose-Hameroff conjecture with conventional understandings of quantum theory, molecular neurobiology and the varying shades of human subjectivity, 
it may be that it will find a place in some future theory of the brain-mind. Roger Penrose remarks from his Platonic perspective that the currently fashionable picture of the brain and mind is a mere shadow of the deeper level of cytoskeletal action - and it is at this deeper level where we must seek the physical basis of mind' (Penrose, 1994, p.376).

\section{Panpsychism}

It all depends on what one means by 'physical'. We noted in the introduction that the seventeenth century scientific revolution based itself on a sharp distinction between matter and mind (or soul). It was only thus that science could escape ecclesiastic control and theological censure. The old Aristotelian science of four causes, of movement from potential into actual, and of a triune or tripartite soul-vegetable, animal and rational - all that great system of thought fell away into desuetude and was ultimately forgotten. Yet for a millennium and a half it had formed the science of the day. It fell into desuetude because the new science of Galileo and his followers proved a far better description and thus tool for manipulating the natural world.

Yet the ultimate outcome of Galilean science, after four hundred years of research, has shown, at least according to the orthodox Copenhagen interpretation, that consciousness cannot be excluded from our account of the natural world. Although, as I argued above, it does not seem likely that quantum physics, or through quantum physics, consciousness can affect the brain's microphysiology and thus, by a multiplication up through layers of complexity, human choice, nevertheless the allusions to consciousness in the works of the great founding fathers of the subject (see Smith, 2006) perhaps points a way forward.

Is it possible, finally to reconnect mind, that is 'experiencing', the presence of 'qualia', of 'subjectivity', with matter through a rapprochement between quantum physics and the often derided thesis of panpsychism? Amongst quantum physicists, David Bohm, whose ideas have recently received something of a second coming, certainly thought so (Bohm, 1990). Panpsychism, as
David Skrbina's recent book (Skrbina, 2005) has emphasised, has always had a following in Western thought. La Mettrie provides an example. Because of the title of his major work, L'Homme Machine, he is often regarded as the supreme materialist. In fact he is the complete opposite (Smith, 1999): He regarded Descartes' mechanistic physiology as a joke ('Descartes that genius made to open up new paths and lose his way' 1747, p.138; 'There is nothing in the whole Universe but a single diversely modified substance, 1747, p.117, etc.). Examples could be multiplied (Skrbina, 2005). Essentially the panpsychist believes that mentality has been part of the world, from the beginning (see Smith, 2000) - that matter has, in other words, and to quote David Bohm once more, 'a mental pole'. This idea has struck many as absurd. Yet, as the quotation which heads this paper suggests, 'when you have excluded the impossible, whatever remains, however improbable, must be the truth'

Can we make sense of this proposition? It is surely absurd to say that sticks and stones and thermostats feel! This is only commonsense. Consciousness is restricted to animate forms. Some would, of course argue that commonsense is not a good guide. For many centuries it was only common sense to believe that the Sun revolved around the Earth. Common sense was spectacularly wrong. But let that pass. Let us suppose that consciousness is restricted to animate creation and indeed to animals and animal brains. How can we reconcile the panpsychist belief in consciousness as a fundamental feature of the universe and the conviction that it is restricted to animal brains and, perhaps, the brains of 'higher' animals at that? What's so special about brains?

One possible answer is 'material complexity'. Brains are commonly said to be the most complex concatenations of matter in the known universe (for discussion see Smith, 1994). But they are more than merely intricate constellations of matter; they are also profoundly unified. They show a property that Denbigh (1975) defines as 'integrality' to an unparalleled degree. The figures are well known. Human brains contain 
well over $10^{10}$ neurons and each receives anything up to 100000 synaptic contacts on its dendritic tree and soma. This is quite different from organs of comparable size, such as the liver. Here the cells may be in vascular contact with each other but have no direct and rapid contact through action potentials and/or electrotonic conduction. Changes in any one part of the brain are likely to elicit changes in every other part.

Brains are also quite different in this regard from their silicon competitors. Remove a circuit from a computer, or a line of code, and disaster promptly ensues. They do not, as the jargon has it, degrade 'gracefully'. Although their wiring diagrams may approach those of more primitive brains in complexity their units are inorganic and burnt into the silicon. This is not how it is with brains. The complexity does not stop at the level of neurons but continues all the way down to the molecular and atomic level, as noted in section 2 above. Aquinas explains the difference nicely when he writes that 'a natural body is distinguished from an artificial body in that in the former the component parts lose their individuality whereas in the latter, like bricks in a wall, their individuality is maintained' (Aquinas, 1274, book 4, §35)

Quantum physics, as we have noted, disabuses us of the notion that atoms and molecules fall under the Newtonian rubric of 'solid, massy, hard, impenetrable Particles'. Stick and ball models of molecules do great disservice in forming the intuition of budding biochemists and molecular biologists. Linus Pauling showed us long ago that the covalent bonds uniting atoms in the simplest molecules involve the sharing of electrons; quantum physicists showed even earlier that the notion of electrons, or indeed atoms, having a precise location has to be abandoned. The common picture of the microworld as consisting of a swarm of miniscule billiard balls bouncing into and against each other could hardly be further from the truth. Rather than organisms and brains being built, stone on stone like some great cathedral, they are generated by the 'flickering' unification of their constituents. It is difficult for the mind bought up under the widespread influence of outmoded science to grasp this reality. In a previous paper (Smith, 2008), I noted that Nietzsche, in the nineteenth century, had had a premonition of this pervasive error in Western thought. In many places and in particular in The Will to Power he points out that for thinkers in the Western tradition 'in order to think and infer it is necessary to assume 'beings'; logic only handles formulae of what remains the same' $(1883 / 8, \S 517)$. He believed that the old 'essentialist' metaphysics was no more than a deeply embedded fiction allowing the 'naked ape', Homo sapiens, to survive and prosper on the Sun's third planet (see, also, Smith, 1987; 1992). This belief, he maintained, 'however necessary it may be for the preservation of the species has nothing to do with the truth...' (Nietzsche, 1883/8, §487).

Thus one possible way of reconciling the panpsychist thesis of mentality 'all the way down' with our conviction that consciousness is only to be found in animals, and perhaps only the so-called 'higher' animals, is to make use of the concept of emergence. This, of course, is a not uncommon move and one made by many thinkers who would be inclined to rubbish panpsychism. These latter thinkers argue that consciousness is the property of brains much as time-keeping is a property of clocks. Consciousness no more inheres in the elements of which a brain is composed than time-keeping inheres in the elements - the cogwheels, the spring, the escapement etc. which make up a clock. But put all the elements together in the appropriate fashion and consciousness springs out of the one as time-keeping springs out of the other. The panpsychist will have nothing to do with this concept of emergence: consciousness is not a property like time-keeping, or, in the computer-analogy, computation. These properties, argues the panpsychist, are 'system-properties', not true emergent properties.

The sense in which the panpsychist wishes to use emergence is that given in the Random House Dictionary of the English Language: 'to come forth into view or notice, as from concealment or obscurity - a ghost is emerging from the grave; a ship emerging from the fog...' (for further discussion see 
Smith, 1983). This can be formalized as follows: "Let " $\mathrm{x}$ " be a complex entity and " $\mathrm{P}$ " $\mathrm{a}$ property possessed by " $\mathrm{x}$ "; then " $\mathrm{P}$ " is an emergent property of " $\mathrm{x}$ " iff it is present but undetected in some or all the components of " $x$ "'. A number of examples may serve to make this concept of emergence clearer.

One of the most interesting of these is gravity itself. The gravitational force between subnuclear particles is 36 orders of magnitude less than the predominating Coulombic forces. It is not detectable by contemporary physical instrumentation. Yet when these subnuclear particles aggregate into atoms and these into stars and planets, gravity emerges as the dominating force in the universe.

It is much the same with the shortrange forces between nucleons. Karl Popper (1947) points out that these forces are not detectable between the 'free-living' nucleons of intergalactic space. Yet when nucleons are crushed together by huge stellar pressures so that they come to within $10^{-15} \mathrm{~m}$ of each other, these forces are 'unveiled'. They then become supremely important in holding together the atoms of which the Universe (including ourselves) is composed.

Finally, as temperatures approach $0^{\circ} \mathrm{K}$, quantum effects normally swamped by thermal statistics emerge into the macroscopic, human, world as the phenomena of superconductivity and superfluidity etc.

These are all examples drawn from the world of physics. They all show that characteristics possessed but undetected by components of the microworld emerge into the macroworld in appropriate circumstances.

A note of caution is appropriate here. All the physical properties of the microworld itemized above could in principle be detected by utopian physical instrumentation: they are all physical properties, all in principle measurable. This, of course, is not the case with mentality. Qualia, as Descartes insisted in the seventeenth century, have no spatial or massive dimensions. So the examples of emergence given above are at best analogies, crutches to help show what the panpsychist has in mind.
For the panpsychist would argue that consciousness, like quantum indeterminism, is a fundamental feature of the universe and, like quantum indeterminism, is in most cases swamped out by the thermal statistics of the macroworld. Only in certain highly peculiar cases, when the conditions are just right, does it 'emerge' into the macroworld. These cases, as I argued above, are provided by the huge integrated complexity of animal (including human) brains.

\section{The Different Forms of Qualia}

The panpsychist argument outlined in the previous section ends by suggesting that although qualia are basic constituents of our universe they only become significant in the unprecedented integral complexity of animal brains. This argument, of course, implies that subjectivity has no evolutionary advantage: it is just a 'brute' fact'. This, of course, seems counter-intuitive and, indeed, objectionable to many, especially, perhaps, to those rose in the humanities where the study of human subjectivity, whether expressed in literature, music or painting, is all-important. But this may be merely our ineluctable bias towards self-importance, towards anthropocentric views of the world. Darwinists might, on the other hand, express some satisfaction. It has never been obvious what part, if any, subjectivity has, or can play, in the 'random variation and selective retention' which powers evolution by natural selection.i.

It cannot be denied, however, that qualia differ throughout our waking lives and, indeed, in dreaming sleep. If subjectivity is the outcome of the integrated outcome of activity in large volumes of cerebral material, according to William James of the entire brain (James, 1890), then why should pain, scents, tastes, views, sounds, 'feel' so very different? This problem is compounded when we recognize that the material substrate, the cerebral microstructure and microphysiology, at the subcellular and molecular level, is largely indistinguishable. This is not to say, of course, that the brain areas to which the special senses project are not distinctively different from each other - the visual areas, auditory areas, olfactory areas in the mammalian brain have been well mapped - 
but that they all have much the same underlying molecular biology.

The best answer to this conundrum is, I believe, that proposed by Llinas and Paré some years ago (Llinas and Paré, 1996). Llinas conceives that an 'oneiric' consciousness, perhaps associated with phase-locked oscillations in wide areas of neocortex, palaeocortex and thalamus, is continuously modified by sensory input (Llinas et al., 1998). An image is provided by the different so-called Chladni figures induced by different vibrations in a thin layer of sand on a metal tray. A similar metaphor is provided by the different vibrations, and consequently different musical tones, engendered by closing the different stops of a wind-instrument such as a flute.

This take on the mind-brain problem is clearly a version of the dual-aspect thesis implicitly accepted by most neuroscientists. It implies that a certain pattern of activity in the brain - the whole brain in this case - is 'experienced' as a certain quality of subjectivity. There is, of course, a huge amount of evidence - experimental, pathological etc. - that this is the case. What is new in the panpsychist thesis is that these qualia are modifications of an underlying consciousness, an oneiric consciousness (to use Llinas's graphic description), which is just a 'brute' consequence of the brain being the intricate integral system, all the way down to the submicroscopic, that it is. It suggests that a computer system which might respond in precisely the same way as the brain responds would, if built 'from the outside' with inorganic units - perhaps dustbin lids to use John Searle's example - would not experience, or live through, the subjectivities we, conscious, creatures live through. It suggests, also, that our conviction that we are persons, responsible for our actions, is, as hinted in section 4, illusory. This, as both Nietzsche (Nietzsche 1883/8: §485) and Bohm (1987), suggest is one of the most difficult, if not the most difficult, implication to accept. It may be the consequence that the Holy Office intuited four hundred years ago when Copernicus and Galileo destroyed the medieval synthesis.

\section{Concluding Remarks}

Thus, to sum up, it seems to me that the focus on synaptology by quantum physicists in an endeavour to preserve freedom of action in a material world (Kant's problem) does not mesh with what molecular biologists now understand about those multitudinous junctions between neurons. I would also argue that the microtubular alternative promoted by Penrose and Hameroff, latterly especially by Hameroff, also fails to pass the test of molecular plausibility. I would argue, instead, with Mackay (1967), that freedom of action is illusory except when the agent is told from the outside of his future behaviour. The conviction we all have that we act out of free will is a deeply embedded adaptation to the sociality enforced on early humans during the long age of the Pliocene.

The existence of qualia, of subjectivity, is, however, it seems to me inescapable. How subjectivity can be tied into the world in which we find ourselves remains the major intellectual problem of our time. I suggest that the panpsychist position is not only not absurd but requires serious consideration and $\mathrm{I}$ give a brief and necessarily overly compact account of how it might be developed in the light of contemporary neuropsychological knowledge. I suggest, in addition, that the insights both physical and philosophical of quantum theory (according to many a calculating device giving no information about ontology) assist this approach. Whether this route out of our difficulties is viable or whether it leads to such unpalatable conclusions that it must be rejected I leave others to judge. I can only end as I began, with the great detective's words of wisdom; 'when you have excluded the impossible, whatever remains, however improbable, must be the truth'. 


\section{References}

Aquinas St Thomas, c.1274, Summa Contra Gentiles, trs. Fathers of the English Dominican Province, 1920.

Beck F. Synaptic quantum tunnelling in brain activity. NeuroQuantology 2008; 6:140-151.

Beck $F$ and Eccles JC. Quantum aspects of consciousness and the role of consciousness. PNAS 1992; 89: 11357-11361

Beck F. Can quantum processes control synaptic emission? International Journal of Neural systems 1996; 7:343-53

Bohm D. 1987, interview with David Peat and John Briggs at http://www.fdavidpeat.com/interviews/bohm.htm

Bohm D. A new theory of the relationship of mind to matter. Philosophical Psychology 1990; 3:271-286

Denbigh KG. In L. Kubat and J. Zeman eds, Entropy and Information in Science and Philosophy. Amsterdam: Elsevier, 1975; 83-92.

Doyle DA, Cabral JM, Pfuetzner RA et al., The structure of the potassium channel: molecular basis of $\mathrm{K}^{+}$ conduction and selectivity. Science 1998; 280: 73

Eccles JC. A unitary hypothesis of mind-brain interaction in the cerebral cortex. Proc Roy Soc B 1990; 240: 433-451

Eccles JC. How the self controls its brain. Berlin: Springer-Verlag, 1994.

Jackson MB, Chapman ER. Fusion pores and fusion machines in $\mathrm{Ca}^{2+}$-triggered exocytosis. Ann Rev Biophys Biomol Struct 2006; 35: 135-160

Jiang $Y$, Lee A, Chen J, Ruta V, Cadene M, Chait BT, Mackinnon R. X-ray structure of a voltagedependent $\mathrm{K}^{+}$channel. Nature 2003; 423: 33-41

James W. Principles of Psychology. 1890; new edition, New York: Dover, 1950.

La Mettrie JO de. L'Homme Machine 1747. Leyden; trs. in Vartanian, A: La Mettrie's Homme Machine: A Study in the Origins of an Idea. Princeton, NJ Princeton University Press, 1960.

Libet B. Do we have free will? Journal of Consciousness Studies 1999. 6: 47-57;

Llinas R and Churchland PS. The Mind-Brain Continuum. Cambridge, MA and London: MIT Press, 1996.

Llinas $\mathrm{R}$ and Paré $\mathrm{D}$. The Brain as a closed system modulated by the senses. In Llinas and Churchland, 1996.

Llinás R., Ribary $U$, Contreras $D$ and Pedroarena C. The neuronal basis for consciousness. Phil Trans Roy Soc B 1998; 353:1841-1849

Lisman JE, Raghavachan S, Tsien RW. The sequence of events that underlie quantal transmission at central glutaminergic synapse. Nature Reviews Neuroscience 2007; 8:597-60.

MacKay D. Freedom of Action in a Mechanistic Universe 1967. Cambridge: Cambridge University Press

Nietzsche F. Will to Power 1883/7. W. Kaufmann and R.J.Hollingdale, Edited. W. Kaufmann, New York: Vintage Books, 1968.

Penrose R. Shadows of the Mind. Oxford: Oxford University Pres, 1994.

Popper K. Quantum physics without "the Observer" In Bunge, M., Ed., Quantum Theory and Reality. Berlin: Springer, 1967.
Skrbina D. Panpsychism in the West. Cambridge, Mass: MIT Press, 2005

Rizzollatti $G$ and Criaghero L. The Mirror-Neuron System', Annual Review of Neuroscience 2004; 27: 169-192

Smith CUM. Anatomical concepts and the problem of mind. J Social and Biol Structs 1983; 6:381-392.

Smith CUM. Clever beasts who invented knowing: Nietzsche's evolutionary biology of knowledge. Biology and Philosophy 1987; 2:1-27

Smith CUM. Kant and Darwin. J Social Biol Structs 1991; 14:35-50

Smith CUM. Zarathustra's evolutionary epistemology. J Social Evol Systems 1992; 15:75-85

Smith CUM. The Complexity of Brains: A Biologist's View, In Complex Systems: Mechanisms of Adpatation. Netherlands: IOS Pres, 1994: 93-100.

Smith CUM. 350th Anniversary of Passions de l'Ame. J Hist Neurosci 1999; 8:221-6

Smith CUM. Evolutionary Biology and the 'Hard Problem'. Evolution and Cognition, 2000; 6:162-75

Smith CUM. Elements of Molecular Neurobiology (3rd edition). Chichester: Wiley, 2002.

Smith CUM. The 'hard problem' and the quantum physicists, part 1: the first generation. Brain and Cognition 2006; 61:181-8.

Smith CUM. The 'hard problem' and the quantum physicists, part 2: modern times. Brain and Cognition 2008; and at <doi:10.1016/j.bandc.2007.09.004>

Stapp HP. Mindful Universe 2004 at http://www-physics.lbl.gov/ stapp/MUl.doc

Wilson EO. Sociobiology: The new synthesis. Boston, Ma: Harvard University Press, 2000. 